\title{
ЭМБРИОНАЛЬНЫЙ МЕТАБОЛИЗМ ОКСИДА АЗОТА И ЕГО СВЯЗЬ С ПОСТЭМБРИОНАЛЬНЫМ РОСТОМ У КУР (Gallus gallus domesticus L.) И ПЕРЕПЕЛОВ (Coturnix coturnix L.)*
}

\section{А.М. ДОЛГОРУКОВАํㅛ, В.Ю. ТИТОВ¹, 2, И.И. КОЧИШ ${ }^{2}$, В.И. ФИСИНИН 1 , И.Н. НИКОНОВ ${ }^{2}$, О.В. КОСЕНКО ${ }^{1}$, О.В. МЯСНИКОВА 2}

Развитие эмбриона сопряжено с интенсивной продукцией оксида азота (NO). Многие процессы, происходящие в эмбриогенезе (в частности, дифференциация тканей, апоптоз), NOзависимы. Однако оперативный контроль метаболитов NO в живых тканях затруднен, и о функциональной активности оксида азота обычно судят по результатам влияния блокаторов его синтеза, так называемых соединений - доноров NO и аргинина как источника NO. Но такой подход не позволяет установить механизм взаимосвязи между проявлением эффектов оксида азота и его метаболизмом. Есть данные, что миогенез также относится к NO-зависимым процессам. Например, сообщалось, что аргинин, блокаторы NO-синтазы и доноры NO влияют на развитие мышц. В то же время имеющиеся результаты довольно противоречивы. Отсутствие данных о связи метаболизма оксида азота и наблюдаемых эффектов не позволяет детализировать предположение о роли оксида азота в миогенезе, определяющих ее механизмах, а следовательно, ограничивает возможность использования NO для коррекции развития организма животного. В настоящем исследовании мы, применив высокочувствительный и высокоспецифичный ферментный сенсор, впервые показали взаимозависимость метаболизма оксида азота в эмбрионе и особенностей постэмбрионального развития у разных видов птицы. Цель работы - изучить связь интенсивности синтеза и окисления NO в эмбрионе с эмбриональным и постэмбриональным ростом птицы и оценить возможность регуляции этого процесса для повышения мясной продуктивности. Эксперименты проводили в условиях вивария (ФГБУ СГЦ «Загорское», ЭПХ ВНИТИП, г. Сергиев Посад, Московская обл., 2017-2019 годы) на курах и перепелах разных пород. Установлено, что оксид азота в эмбрионах птиц одного вида синтезируется со сравнительно равной интенсивностью. Об этом судили по суммарной концентрации всех метаболитов NO и в большинстве случаев достоверных расхождений не обнаружили. В то же время резко разнится интенсивность окисления NO до нитрата. По этому показателю различия между эмбрионами яичных и мясных пород, линий и кроссов достигают нескольких порядков. В эмбрионах яичных происходит преимущественно накопление оксида азота в составе соединений-доноров. К концу эмбриогенеза их концентрация достигает нескольких сотен микромолей. В эмбрионах мясных пород преобладает окисление NO до нитрата. Внутри породы, линии и кросса показатель интенсивности окисления NO варьирует не более чем на 10-15 \%. Показано, что окисление происходит в основном в мышечной ткани. Экзогенно введенные в эмбрион доноры NO окисляются с той же интенсивностью, что и эндогенно синтезированные. Блокатор синтеза NO снижал общее содержание его метаболитов, но не изменял количественного соотношения между донорами NO и нитратом. Следовательно, анализируемый показатель связан с особенностями тканей эмбриона и интенсивность окисления NO в эмбрионе служит, таким образом, маркером этих особенностей. Она коррелирует с мясной продуктивностью и является показателем, присущим породе, линии и кроссу. Этот показатель не сцеплен с полом эмбриона, не зависит от возраста несушки и условий ее содержания. Он может полностью или частично наследоваться. Таким образом, это очень чувствительный и специфичный генетически обусловленный показатель. Двукратное изменение количества окисленного NO при использовании доноров NO и блокаторов его синтеза не оказало достоверного влияния на скорость прироста живой массы. Механизм эмбрионального окисления NO и его взаимосвязи с развитием мышечной ткани пока неизвестен.

Ключевые слова: домашняя птица, оксид азота, доноры NO, нитрат, эмбриогенез, постэмбриональный рост.

Известно, что эмбриогенез сопровождается синтезом NO (1-4). Считается, что многие процессы, происходящие в развивающемся эмбрионе, например имплантация (5), дифференциация клеток и апоптоз (6, 7), адаптация к гипоксии (8), NO-зависимы. По имеющимся данным, оксид азота влияет на развитие мышц $(9,10)$. Это показано как на клеточном (11-14),

* Исследование выполнено при финансовой поддержке РФФИ в рамках научного проекта № 20-016-00204-а. 794 
так и на организменном $(13,15,16)$ уровне, и в том числе на эмбриональном $(9,17)$. Выводы были сделаны на основании экспериментов с соединениями - донорами NO $(9,11,18)$, изучения последствий блокирования синтеза NO $(9,10,12,13)$, использования аргинина как источника NO (9, $12,17)$. Полученные эффекты довольно противоречивы и не позволяют детально предположить какой-либо механизм влияния NO на миогенез. Недостаток всех предыдущих исследований, с нашей точки зрения, заключаются в отсутствии контроля метаболизма используемых препаратов и изначального содержания NO в тканях. Такой контроль до сих пор был методологически проблематичен $(19,20)$, но он необходим для выяснения механизма участия NO в физиологических процессах.

При помощи высокочувствительного ферментного сенсора, позволяющего определять содержание всех физиологически значимых нитро- и нитрозосоединений (20), нами ранее выявлены основные закономерности синтеза и метаболизма оксида азота в птичьем эмбрионе (21). Было установлено, что в эмбрионах пород, линий и кроссов, полученных в результате селекции на улучшение мясной продуктивности, происходит интенсивное окисление синтезируемого в эмбрионе NO до нитрата. В эмбрионах исходных и яичных форм NO накапливается преимущественно в составе так называемых соединений-доноров NO - нитрозотиолов (RSNO), динитрозильных комплексов железа (ДНКЖ), высокомолекулярных нитросоединений $\left(\mathrm{RNO}_{2}\right)$, способных трансформироваться в ДНКЖ. Разность в интенсивности окисления NO между мясными и яичными формами может быть до двух порядков (21).

В настоящем сообщении представлены данные о взаимосвязи между интенсивностью синтеза и метаболизма оксида азота (NO) в эмбрионе, с оной стороны, и эмбриональным и постэмбриональным развитием птиц с другой. Впервые показано, что окисление NO до нитрата происходит преимущественно в мышечном каркасе. Именно интенсивность этого окисления коррелирует с мясной продуктивностью. Она определяется генетически обусловленными особенностями эмбриональных тканей, и эти особенности связаны со скоростью роста мышечной ткани.

Цель работы - выполнить количественный анализ интенсивности синтеза и окисления оксида азота в эмбрионе и сопоставить эти процессы с показателями эмбрионального и постэмбрионального роста птицы, чтобы оценить возможность его регуляции с участием NO для повышения мясной продуктивности.

Методика. В экспериментах использовали оплодотворенные яйца кур (Gallus gallus domesticus L.) пород андалузская голубая, юрловская голосистая, корниш (линия Б56), плимутрок (линия Б79), малайская бойцовая и куланги, кроссов Хайсекс белый (Hisex White), Смена 8, Cobb 500, Ross 308, а также перепелов (Coturnix coturnix L.) пород эстонская мясо-яичная, японская серая, маньчжурская золотистая, белая тяжелая (получены в ООО «Генофонд», Россия). Исследования проводили в условиях вивария (ФГБУ СГЦ Загорское, ЭПХ ВНИТИП, г. Сергиев Посад, Московская обл.) в 2017-2019 годах.

Яйца (по 70 шт. для каждой породы и кросса) помещали в инкубаторы (Стимул-Инк-1000, ООО «Стимул Групп», Россия); температура в инкубационный период $-37,6^{\circ} \mathrm{C}$, в выводной период $-37,2{ }^{\circ} \mathrm{C}$. Массу каждого яйца определяли перед закладкой на инкубацию.

Перед закладкой, а также на 7-е и 17-е сут инкубации у кур и ежесуточно с 1-х по 13-е сут - у перепелов отбирали по 4 яйца для каждой 
породы, линии и кросса. Из этих яиц извлекали эмбрионы для количественного определения метаболитов NO (анализ выполняли не позднее, чем через 30 мин после отбора образцов). Для получения гомогенатов тканей эмбриона механически измельченные навески заливали 158 мМ раствором хлорида натрия, содержащим 10 мМ фосфата калия, pH 7,4 (в расчете 1 г ткани на 20 мл раствора) и обрабатывали в стеклянном гомогенизаторе (8 мин, 40 фрикций в мин, $\left.6{ }^{\circ} \mathrm{C}\right)$. При получении гомогенатов целого эмбриона аналогичной процедуре подвергали содержимое яйца, лишенного скорлупы.

Динитрозильный комплекс железа с двумя молекулами глутатиона (ДНКЖ/GSH), полученный по методике, описанной ранее $(19,20)$, использовали в качестве экзогенного соединения - донора NO. Для блокирования синтеза NO применяли L-нитроаргинин (HA) («Sigma-Aldrich», США). Pacтворы донора и блокатора готовили на стерильном физиологическом растворе и вводили in ovo в воздушную камеру перед закладкой яиц на инкубацию согласно схеме эксперимента: 0,3 мл физраствора (контроль), 0,3 мл 13,0 мМ ДНКЖ/GSH (донор), 0,3 мл 6,0 мМ НА (блокатор).

Для количественного анализа метаболитов NO применяли разработанный нами ферментный сенсор, основанный на способности нитрита, нитрозоаминов (RNNO), нитрозотиолов (RSNO), динитрозильных комплексов железа (ДНКЖ) и нитропроизводных высокомолекулярных соединений $\left(\mathrm{RNO}_{2}\right)$ ингибировать каталазу в присутствии галоид-ионов и на утрате этого свойства под действием факторов, специфичных для каждой группы соединений. Содержание нитрата оценивали после восстановления треххлористым ванадием до нитрита с последующим количественным определением (20). Метод позволяет измерить количество производных NO с чувствительностью до 50 нМ без предварительной подготовки образца (20). Основу установки для количественного анализа составлял прибор Dithermanal («Vaskut-EMG», Венгрия).

Также использовали классический метод для определения нитрита с реактивом Грисса (22).

Выведенный молодняк выращивали в клетках КБН-1640 по 20 гол. до 10-х сут и по 8-10 гол. - с 10-х по 28-е сут. Кормление - в соответствие с рекомендациями ВНИТИП для возраста и породы (кросса) (М., 2014). Рост контролировали взвешиванием каждой особи в 1-е, на 14-е и 28-е сут.

Результаты представлены в виде средних значений $(M)$ и стандартных ошибок средних $( \pm \mathrm{SEM})$. Оценку достоверности различий между сравниваемыми показателями проводили с помощью $t$-критерия Стьюдента. Различия считали статистически значимыми при $\mathrm{p}<0,05$.

Результаты. Синтез и окисление NO в птичьем эмбрионе. Развитие птичьего эмбриона сопровождается интенсивной продукцией оксида азота. Синтезированный NO, согласно современным представлениям, включается в состав так называемых соединений - доноров NO. Предполагается, что именно эти соединения непосредственно взаимодействуют с физиологической мишенью (19, 23-25). Как видно из данных, представленных на рисунке, к 3-м сут общая концентрация метаболитов NO - доноров NO и нитратов в гомогенате содержимого перепелиного яйца достигает 150 мкмоль/л. Аналогичную зависимость мы обнаружили у кур (21). При этом соединения - доноры NO накапливаются в амнионе, а нитрат - за пределами амниотического пузыря. Нитрит и нитрозоамины во всех тканях эмбриона содержались в следовых количествах (25). С 3-х по 6-е сут у перепелов (см. рис.) и 11-е у кур (21) общее содержание нитро- и 
нитрозосоединений в гомогенате эмбриона практически неизменно. Далее показатель резко увеличивается (см. рис.), что связано с началом интенсивного синтеза NO в тканях зародыша (21).
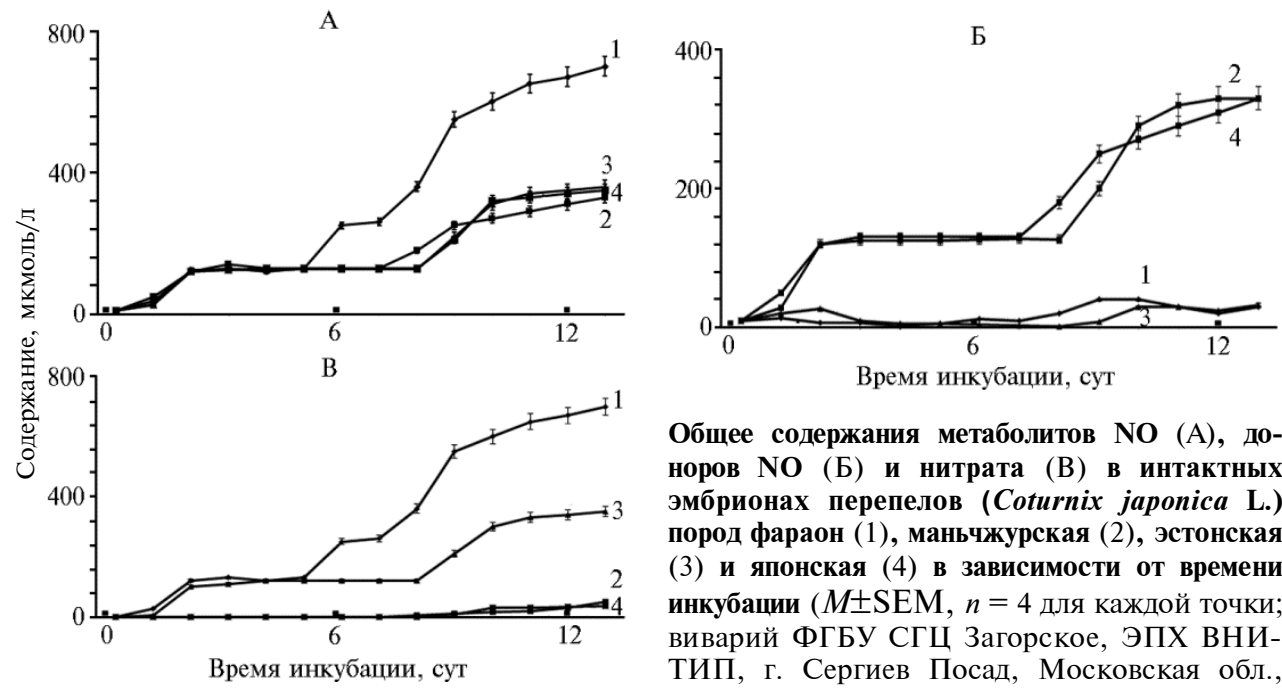

Общее содержания метаболитов NO (A), доноров NO (Б) и нитрата (B) в интактных эмбрионах перепелов (Coturnix japonica L.) пород фараон (1), маньчжурская (2), эстонская (3) и японская (4) в зависимости от времени инкубации ( $M \pm \mathrm{SEM}, n=4$ для каждой точки; виварий ФГБУ СГЦ Загорское, ЭПХ ВНИТИП, г. Сергиев Посад, Московская обл., 2017-2019 годы).

1. Соотношение метаболитов NO (нитраты и доноры NO, мкмоль/л) в гомогенатах интактных 7-суточных эмбрионов кур и перепелов разных пород, линий и кроссов в сравнении с динамикой живой массы $(M \pm \mathrm{SEM}, n=50$ каждой породы, линии, кросса; виварий ФГБУ СГЦ Загорское, ЭПХ ВНИТИП, г. Сергиев Посад, Московская обл., 2017-2019 годы)

\begin{tabular}{|c|c|c|c|c|c|c|}
\hline \multirow{3}{*}{ Порода, линия, кросс } & \multirow{3}{*}{$\begin{array}{l}\text { Масса } \\
\text { яйца, г }\end{array}$} & \multicolumn{4}{|c|}{ Масса птенца, г } & \multirow{3}{*}{$\begin{array}{l}\text { Соотношение } \\
\text { метаболитов } \\
\text { NO, 7-е сут }\end{array}$} \\
\hline & & \multirow{2}{*}{ 1-е сут } & \multirow{2}{*}{ 14-е сут } & \multicolumn{2}{|c|}{$28-\mathrm{e}$ сут } & \\
\hline & & & & 9 & $\hat{0}$ & \\
\hline \multicolumn{7}{|c|}{ К у р ы (Gallus gallus domesticus L.) } \\
\hline Хайсекс белый & $64,2 \pm 0,8$ & $42,4 \pm 3,1$ & $79,8 \pm 3,9$ & \multicolumn{2}{|c|}{$222,4 \pm 5,2$} & $\frac{<0,1}{138,9 \pm 8,9}$ \\
\hline Смена 8 & $64,8 \pm 0,6$ & $47,5 \pm 0,7$ & $311,9 \pm 19,2$ & \multicolumn{2}{|c|}{$1157,0 \pm 50,0$} & $\frac{145,4 \pm 9,8}{3,3 \pm 2,1}$ \\
\hline Cobb 500 & $62,7 \pm 0,7$ & $48,5 \pm 1,9$ & $276,5 \pm 17,5$ & \multicolumn{2}{|c|}{$1244,5 \pm 38,4$} & $\frac{151,3 \pm 10,1}{2,3 \pm 1,5}$ \\
\hline Юрловская голосистая & $60,4 \pm 0,7$ & $39,1 \pm 0,8$ & $107,5 \pm 4,5$ & \multicolumn{2}{|c|}{$241,7 \pm 8,9$} & $\frac{<0,1}{149,6 \pm 9,1}$ \\
\hline Малайская бойцовая & $54,5 \pm 0,5$ & $37,9 \pm 0,8$ & $98,8 \pm 4,4$ & \multicolumn{2}{|c|}{$214,8 \pm 9,1$} & $\frac{148,4 \pm 9,3}{5,8 \pm 1,9}$ \\
\hline Орловская ситцевая & $51,7 \pm 0,5$ & $35,5 \pm 0,9$ & $93,1 \pm 5,8$ & \multicolumn{2}{|c|}{$167,8 \pm 8,7$} & $\frac{<0,1}{131,5 \pm 6,9}$ \\
\hline Андалузская голубая & $48,5 \pm 0,6$ & $37,2 \pm 0,97$ & $85,4 \pm 3,1$ & \multicolumn{2}{|c|}{$170,6 \pm 5,4$} & $\frac{<0,1}{141,8 \pm 8,4}$ \\
\hline Куланги & $55,7 \pm 0,6$ & $41,3 \pm 0,9$ & $92,4 \pm 3,8$ & \multicolumn{2}{|c|}{$223,7 \pm 8,3$} & $\frac{143,4 \pm 7,6}{8,8 \pm 1,6}$ \\
\hline Корниш Б56 & $65,8 \pm 0,6$ & $49,3 \pm 0,7$ & $291,7 \pm 9,4$ & \multicolumn{2}{|c|}{$1287,5 \pm 49,1$} & $\frac{152,2 \pm 9,9}{9,5 \pm 1,7}$ \\
\hline Плимутрок Б79 & $64,3 \pm 0,8$ & $44,9 \pm 0,7$ & $265,2 \pm 9,7$ & \multicolumn{2}{|c|}{$1058,4 \pm 32,6$} & $\frac{<0,1}{141,8 \pm 8,4}$ \\
\hline Ross 308 & $65,6 \pm 0,7$ & $43,4 \pm 0,5$ & $341,7 \pm 10,1$ & \multicolumn{2}{|c|}{$1146,4 \pm 30,5$} & $\frac{138,5 \pm 8,6}{4,4 \pm 1,9}$ \\
\hline \multicolumn{7}{|c|}{ П е р е п е л а (Coturnix japonica L.) } \\
\hline Маньчжурская золотистая & $12,7 \pm 0,2$ & $11,7 \pm 0,2$ & $95,8 \pm 1,1$ & $178,2 \pm 3,7$ & $163,6 \pm 1,7$ & $\frac{<0,1}{131,8 \pm 4,3}$ \\
\hline Эстонская & $13,0 \pm 0,1$ & $12,1 \pm 0,2$ & $111,0 \pm 1,1$ & $194,5 \pm 3,8$ & $181,8 \pm 2,3$ & $\frac{139,4 \pm 11,2}{3,1 \pm 1,5}$ \\
\hline †Маньчжурская × ðౌэстонская & $13,6 \pm 0,2$ & $12,6 \pm 0,2$ & $109,3 \pm 1,4$ & $184,6 \pm 4,1$ & $176,9 \pm 3,8$ & $\frac{168,5 \pm 10,9}{1,5 \pm 0,8}$ \\
\hline Японская серая & $12,2 \pm 0,2$ & $10,6 \pm 0,3$ & $95,6 \pm 1,2$ & $163,5 \pm 2,7$ & $158,1 \pm 3,3$ & $\frac{<0,1}{134,3 \pm 2,7}$ \\
\hline фЯпонская × ふээтонская & $12,1 \pm 0,1$ & $10,4 \pm 0,3$ & $98,7 \pm 1,4$ & $171,3 \pm 2,4$ & $167,5 \pm 2,1$ & $\frac{168,5 \pm 10,9}{1,5 \pm 0,8}$ \\
\hline
\end{tabular}




\begin{tabular}{|c|c|c|c|c|c|c|}
\hline \multirow[b]{2}{*}{ Фараон } & \multirow[b]{2}{*}{$13,4 \pm 0,1$} & \multirow[b]{2}{*}{$11,9 \pm 0,2$} & \multirow[b]{2}{*}{$105,2 \pm 1,6$} & \multirow[b]{2}{*}{$205,1 \pm 3,4$} & \multicolumn{2}{|c|}{ Продолжение таблицы } \\
\hline & & & & & $198,6 \pm 6,0$ & $\frac{235,3 \pm 12,8}{12,8 \pm 1,9}$ \\
\hline Белая тяжелая & $13,5 \pm 0,2$ & $10,9 \pm 0,2$ & $105,0 \pm 2,6$ & $283,3 \pm 3,1$ & $277,4 \pm 6,1$ & $\frac{157,0 \pm 6,7}{3,1 \pm 1,0}$ \\
\hline † Манчьжурская $\times \delta^{-}$японская & $12,6 \pm 0,1$ & $10,2 \pm 0,1$ & $96,3 \pm 0,8$ & $179,4 \pm 2,9$ & $165,2 \pm 2,3$ & $\frac{\leq 0,1}{131,0 \pm 4,8}$ \\
\hline
\end{tabular}

До этого срока суммарное содержание доноров NO и продукта его окисления - нитрата в эмбрионах всех пород одного вида птиц примерно одинаковое (см. рис., табл. 1). В то же время у разных пород, линий и кроссов эмбрионы различались по соотношению нитрата и доноров NO. B пределах одного вида это соотношение может варьироваться на несколько порядков (см. табл. 1). Как было установлено нами ранее, это связано с тем, что в одних эмбрионах NO интенсивно окисляется до нитрата, а в других преимущественно накапливается в составе соединений-доноров (21). Это окисление начинается на 2-е-3-и сут и продолжается на протяжении всего эмбриогенеза (см. рис.).

Высокая интенсивность окисления характерна для особей мясного направления продуктивности. Она наблюдается у эмбрионов бройлеров (Cobb 500, Смена 8, Ross 308), их отцовской линии корниш Б56, также у эмбрионов бойцовских пород (малайская бойцовая, куланги). Для их эмбрионов характерно низкое содержание доноров NO (от единиц до десятков микромолей на литр) при высоком содержании нитрата (сотни микромолей на литр) (см. табл. 1). У эмбрионов яичных пород (Хайсекс, орловская ситцевая, юрловская голосистая, андалузская голубая), а также у материнской линии плимутрок Б79 кросса Смена 8 интенсивность окисления NO минимальна, что показывает соотношение нитрата и доноров NO (см. рис., табл. 1). По аналогии для эмбрионов тяжелых пород перепелов (фараон, белая тяжелая, эстонская) характера высокая интенсивность окисления оксида азота в эмбрионе, в то время как у легких (японская серая, маньчжурская золотистая) окисление незначительно (см. табл. 1).

Взаимосвязь эмбрионального окисления NO и скорости роста птицы. Анализ содержания нитро- и нитрозосоединений в тканях 17-суточных куриных эмбрионов, характеризующихся как высокой, так и низкой интенсивностью окисления NO, показывает, что во всех случаях наибольшее количество соединений - доноров NO аккумулируется в печени. Но в печени, как и в желудочно-кишечном тракте, содержатся преимущественно доноры оксида азота, а количество нитрата незначительно. Значительное накопление нитрата, многократно превосходящее таковое доноров NO, имело место в гомогенате мышечного каркаса эмбриона линии корниш Б56. У линии кросса Хайсекс белый мышечный каркас содержал преимущественно доноры NO (табл. 2). Иными словами, нитрат накапливается в основном в мышечной ткани. Именно в ней, по-видимому, и происходит окисление NO до нитрата. Это дает еще одно основание предполагать, что процесс окисления NO в эмбрионе в основном связан с миогенезом, причем с миогенезом скелетных мышц (см. табл. 2).

Согласно данным, полученных нами ранее, нет качественной разницы в содержании доноров NO и нитрата между грудными и ножными мышцами кур и перепелов. У мясных форм преобладает нитрат, у яичных доноры NO. Количественные различия в содержании метаболитов NO между этими группами мышц одной особи - не более $10-12$ \% $(21,26)$, что 
не идет ни в какое сравнение с разницей между яичными и мясными формами (см. табл. 2). То есть окисление NO прямо не связано с биохимическими особенностями этих групп мышц. Так как мышечная ткань доминирует по массе над другими, в гомогенатах эмбрионов мясных форм преобладает нитрат (см. рис.).

2. Содержание (нмоль/мг) нитро- и нитрозосоединений в тканях 17-суточных интактных эмбрионов у яичного кросса кур (Gallus gallus domesticus L.) Хайсекс белый и мясной линии корниш Б56 $(M \pm S E M, n=8$; виварий ФГБУ СГЦ Загорское, ЭПХ ВНИТИП, г. Сергиев Посад, Московская обл., 20172019 годы)

\begin{tabular}{l|c|c|c|c|c|c}
\hline \multirow{2}{*}{ Кросс } & \multicolumn{2}{|c|}{ Печень } & \multicolumn{2}{c}{ Желудочно-кишечный тракт } & \multicolumn{2}{c}{ Мышечный каркас } \\
\cline { 2 - 6 } & доноры NO & $\mathrm{NO}^{-}$ & доноры NO & $\mathrm{NO}^{-}$ & доноры NO & $\mathrm{NO}^{-}$ \\
\hline Хайсекс белый & $11,5 \pm 0,9$ & $<0,1$ & $1,1 \pm 0,1$ & $<0,1$ & $3,2 \pm 0,3$ & $0,3 \pm 0,1^{*}$ \\
Корниш Б56 & $33,5 \pm 0,3$ & $0,2 \pm 0,1$ & $4,3 \pm 0,3$ & $<0,1$ & $0,2 \pm 0,1$ & $4,2 \pm 0,3^{*}$ \\
Пр и м е ч а н и е. Содержание нитрита и нитрозоаминов во всех образцах $<0,1$ нмоль $/$ мг. \\
* Различия с показателями в других органах статистически значимы при $\mathrm{p}<0,05$. \\
\hline
\end{tabular}

Мы установили, что через 8-15 сут после вывода количество доноров NO и нитрата в тканях цыплят резко снижается и становится примерно одинаковым у всех пород, линий и кроссов (21). То есть высокое содержание нитро- и нитрозосоединений и интенсивное окисление доноров NO до нитрата в мышечной ткани - эмбриональные явления. Также показано, что развитие мышечной ткани у эмбрионов с высокой и низкой интенсивностью окисления NO идет с одинаковой скоростью и не имеет качественной разницы по каким-либо параметрам (26). Различие может быть в интенсивности роста мышечной ткани. Но как ее оценить? У бройлеров выход потрошенной тушки не более чем на 5 \% выше, чем у яичных пород. И этот выход во всех случаях возрастает с увеличением живой массы (21). Именно живую массу мы решили использовать в качестве критерия роста мышечной и костной ткани.

На 1-е сут после вывода цыплята разных пород различаются по живой массе незначительно (см. табл. 1). Рост массы у эмбрионов с высокой и низкой интенсивностью эмбрионального окисления NO, исходя из данных таблицы 3, также происходит без достоверных различий. Однако после вывода у цыплят наблюдаются достоверные различия в росте (см. табл. 1).

3. Масса интактных эмбрионов (г) у перепелов (Coturnix coturnix L.) в зависимости от времени инкубации ( $M \pm \mathrm{SEM}, n=8$; виварий ФГБУ СГЦ Загорское, ЭПХ ВНИТИП, г. Сергиев Посад, Московская обл., 2017-2019 годы)

\begin{tabular}{l|c|c|c|c|c}
\hline \multirow{2}{*}{ Порода } & \multicolumn{5}{c}{ Время инкубации, сут } \\
\cline { 2 - 6 } & 8 & 10 & 12 & 15 & 1 -е сут после вывода \\
\hline Маньчжурская золотистая & $0,53 \pm 0,02$ & $1,23 \pm 0,08$ & $2,63 \pm 2,1$ & $5,32 \pm 3,1$ & $11,7 \pm 0,2$ \\
Фараон & $0,57 \pm 0,02$ & $1,20 \pm 0,10$ & $2,75 \pm 2,1$ & $5,34 \pm 3,4$ & $11,9 \pm 0,2$ \\
\hline
\end{tabular}

Разница по живой массе и скорости ее прироста между бройлерами и яичными курами, как и между тяжелыми и легкими породами перепелов очевидна (см. табл. 1). Но корниш и плимутрок - отцовская и материнская линии кросса Смена 8, характеризующиеся соответственно высокой и низкой интенсивностью эмбрионального окисления NO, различались по живой массе незначительно. Достоверное различие $(\mathrm{p}<0,05)$ имело место лишь на 3-й нед после вывода. Между бойцовыми породами и яичными породами юрловская голосистая и Хайсекс значительной разницы в живой массе не наблюдалось (см. табл. 1).

Перепела тяжелых (фараон, белая тяжелая, эстонская) и легких (японские серые, маньчжурские золотистые) пород явно различались по 
живой массе $(\mathrm{p}<0,05)$. В эмбрионах гибридов японской серой и эстонской, а также маньчжурской золотистой и эстонской пород, судя по соотношению нитрата и доноров NO на 7-е сут, эмбриональное окисление оксида азота происходит с высокой интенсивностью (она не ниже, чем у эмбрионов эстонской породы). По живой массе эти гибриды занимали промежуточное положение между родительскими породами. В то же время гибриды маньчжурской золотистой и японской серой пород по живой массе и интенсивности окисления NO были аналогичны родителям (см. табл. 1).

Возникают два вопроса. Каков механизм взаимосвязи окисления NO и скорости прироста живой массы, обусловленной прежде всего развитием костной и мышечной ткани? И можно ли управлять этим процессом для повышения мясной продуктивности?

Экзогенные соединения - доноры NO, введенные в яйца перед инкубацией, подвергались окислению до нитрата в тех эмбрионах, где имело место интенсивное окисление эндогенно синтезированного NO (Ross 308), и практически не окислялись там, где последний не окислялся (Хайсекс белый) (табл. 4).

4. Содержание (мкмоль/л) доноров $\mathrm{NO}$ и $\mathrm{NO}^{-}$в гомогенатах 7-суточных эмбрионов у кроссов кур (Gallus gallus domesticus L.) под влиянием экзогенного блокатора синтеза NO и препарата ДНКЖ/GSH, введенных перед инкубацией $(M \pm \mathrm{SEM}, n=25$ для каждой группы; виварий ФГБУ СГЦ Загорское, ЭПХ ВНИТИП, г. Сергиев Посад, Московская обл., 2017-2019 годы)

\begin{tabular}{cc|c}
\hline \multicolumn{1}{c|}{ Вариант } & Доноры NO & $\mathrm{NO}^{-}$ \\
\hline Кросс Хайсекс белый: & & $<0,1$ \\
+ 0,3 мл физраствора (контроль) & $138,3 \pm 7,8$ & $<0,1$ \\
+ 0,3 мл 13,0 мМ ДНКЖ/GSH & $210,9 \pm 9,4^{*}$ & $<0,1$ \\
+ 0,3 мл 6,0 мМ НА & $39,8 \pm 3,1^{*}$ & $131,2 \pm 7,5$ \\
Кросс Rоss 308: & & $165,0 \pm 8,3^{*}$ \\
+ 0,3 мл физраствора (контроль) & $3,7 \pm 1,2$ & $179,6 \pm 8,1^{*}$ \\
+ 0,3 мл 5,0 мМ ДНКЖ/GSH & $3,9 \pm 1,3$ & $46,7 \pm 4,2^{*}$ \\
+ 0,3 мл 13,0 мМ ДНКЖ/GSH & $34,1 \pm 2,9$ & $3,6 \pm 1,2$ \\
+ 0,3 мл 6,0 мМ НА & & \\
\hline
\end{tabular}

П р и м е ч а н и е. HA - N $\omega$-нитро-L-аргинин, ДНКЖ/GSH - динитрозильный комплекс железа с двумя молекулами глутатиона. Содержание нитрита и нитрозоаминов во всех образцах $<0,1$ мкмоль/л.

* Различия с соответствующими контролями статистически значимы при р $<0,05)$.

Следовательно, интенсивность окисления определяется некими особенностями тканей эмбриона. Исходя из данных таблицы 2, можно предположить, что окисление происходит в мышечной ткани. Эти особенности определяются генетически, поскольку присущи конкретным породам, линиям и кроссам вне зависимости от возраста несушки, условий ее содержания и условий инкубации яиц (21), а также могут полностью или частично наследоваться (см. табл. 1). С ними как-то связана интенсивность постэмбрионального роста. В таком случае в качестве объяснения можно предложить, что оксид азота интенсивно окисляется в эмбрионе, а связанные с этим процессом фенотипические проявления наблюдаются уже после вывода (см. табл. 1).

Таким образом, окисление NO служит маркером наличия таких особенностей, которые, по-видимому, способны проявляться не только в эмбриональный, но и в постэмбриональный период. Этот маркер может быть использован как для определения фенотипически невыраженных форм (27), так и, возможно, для контроля селекционного процесса.

Следовательно, если интенсивность окисления эндогенного NO низкая, то экзогенное добавление соединений - доноров NO, по всей видимости, не должно иметь какого-либо эффекта. Или, если подобный эффект все же проявляется, то он не связан с NO. Согласно нашим данным, экзогенные 
доноры NO при введении в эмбрион как яичных, так и мясных кур в концентрациях, используемых в таблице 4, не оказывали достоверного влияния на живую массу цыплят в течение первых 3 нед после вывода (p > 0,05).

Использование блокаторов NO-синтазы снижало количество нитрои нитрозосоединений в эмбрионе, не изменяя соотношения между донорами NO и нитратом (см. табл. 4). Снижение общего количества доноров NO и нитрата на $70 \%$ достоверно не сказывалось на приросте живой массы в первые три недели после вывода $(\mathrm{p}>0,05)$. То есть дать однозначный ответ, влияет ли само окисление NO на миогенез, или это окисление есть побочный эффект специфических процессов в развивающихся мышцах эмбрионов мясных форм, мы пока не можем.

Итак, нами установлено, что интенсивность синтеза оксида азота в эмбрионах птиц одного вида примерно одинакова, тогда как интенсивность окисления NO до нитрата разнится (до нескольких порядков при сравнении яичных и мясных пород, линий и кроссов). У яичной птицы оксид азота в эмбрионах накапливается в количестве до нескольких сотен микромолей преимущественно в составе соединений-доноров, у мясной - преобладает окисление NO до нитрата. Внутри породы, линии и кросса интенсивность окисления NO варьирует не более чем на 10-15 \%. Окисление происходит в основном в мышечной ткани. Экзогенные доноры NO окисляются в эмбрионе с той же интенсивностью, что и эндогенные, а блокатор синтеза NO, снижая общую концентрацию его метаболитов, не влияет на количественное соотношение между донорами NO и нитратом. Следовательно, интенсивность эмбрионального окисления есть биохимический маркер экспрессии генов, обусловливающих скорость роста мышечной массы. Идентификация этих генов - важная научная и практическая задача. Возможность регуляции мясной продуктивности на эмбриональном уровне видится прежде всего в регуляции экспрессии этих генов.

\section{ЛИТЕРАТ У РА}

1. Tiwari M., Prasad S., Pandey A., Premkumar K., Tripathi A., Gupta A., Chetan D., Yadav P., Shrivastav T., Chaube S. Nitric oxide signaling during meiotic cell cycle regulation in mammalian oocytes. Frontiers in Bioscience (Scholar Edition), 2017, 9: 307-18 (doi: 10.2741/s489).

2. Khan H., Kusakabe K., Wakitani S., Hiyama M., Takeshita A., Kiso Y. Expression and localization of NO synthase isoenzymes (iNOS and eNOS) in development of the rabbit placenta. $J$. Reprod. Dev., 2012, 58(2): 231-236 (doi: 10.1262/jrd.11-128t).

3. Von Mandach U., Lauth D., Huch R. Maternal and fetal nitric oxide production in normal and abnormal pregnancy. Journal of Maternal-Fetal and Neonatal Medicine, 2003, 13(1): $22-27$ (doi: 10.1080/jmf.13.1.22.27).

4. Blum J., Morel C., Hammon H., Bruckmaier R., Jaggy A., Zurbriggen A., Jungi T. High constitutional nitrate status in young cattle. Comparative Biochemistry and Physiology A-Molecular \& Integrative Physiology, 2001, 130(2): 271-282 (doi: 10.1016/s1095-6433(01)00390-7).

5. Battaglia C., Ciottii P., Notarangelo L., Fratto R., Facchinetti F., De Aloysio D. Embryonic production of nitric oxide and its role in implantation: a pilot study. Journal of Assisted Reproduction and Genetics, 2003, 20(11): 449-454 (doi: 10.1023/B:JARG.0000006706.21588.0d).

6. Kim Y., Chung H., Simmons R., Billiar T. Cellular non-heme iron content is a determinant of nitric oxide-mediated apoptosis, necrosis, and caspase inhibition. J. Biol. Chem., 2000, 275(15): 10954-10961 (doi: 10.1074/jbc.275.15.10954).

7. Li J., Billiar T., Talanian R., Kim Y. Nitric oxide reversibly inhibits seven members of the caspase family via S-nitrosylation. Biochemical and Biophysical Research Communications, 1997, 240(2): 419-424 (doi: 10.1006/bbrc.1997.7672).

8. Malyshev I., Zenina T., Golubeva L., Saltykova V., Manukhina E., Mikoyan V., Kubrina L., Vanin A. NO-dependent mechanism of adaptation to hypoxia. Nitric Oxide, 1999, 3(2): 105-113 (doi: 10.1006/niox.1999.0213).

9. Cazzato D., Assi E., Moscheni C., Brunelli S., De Palma C., Cervia D., Perrotta C., Clementi E. Nitric oxide drives embryonic myogenesis in chicken through the upregulation of myogenic differentiation factors. Experimental Cell Research, 2014, 320 (2): 269-280 (doi: 10.1016/j.yexcr.2013.11.006). 
10. Stamler J., Meissner G. Physiology of nitric oxide in skeletal muscle. Physiol Rev., 2001, 81(1): 209-237 (doi: 10.1152/physrev.2001.81.1.209).

11. Ulibarri J., Mozdziak P., Schultz E., Cook C., Best T. Nitric oxide donors, sodium nitroprusside and S-nitroso-N-acetylpencillamine, stimulate myoblast proliferation in vitro. In Vitro Cell Dev. Biol. Anim., 1999, 35(4): 215-218 (doi: 10.1007/s11626-999-0029-1).

12. Long J., Lira V., Soltow Q., Betters J., Sellman J., Criswell D. Arginine supplementation induces myoblast fusion via augmentation of nitric oxide production. J. Muscle Res. Cell Motil., 2006, 27(8): 577-584 (doi: 10.1007/s10974-006-9078-1).

13. Anderson J.E. A role for nitric oxide in muscle repair: nitric oxide-mediated activation of muscle satellite cells. Molecular Biology of the Cell, 2000, 11(5): 1859-1874 (doi: 10.1091/mbc.11.5.1859).

14. Lee H., Baek M., Moon K., Song W., Chung Ch., Ha D., Kang M-S. Nitric Oxide as a messenger molecule for myoblast fusion. J. Biol. Chem., 1994, 269(20): 14371-4.

15. Ribeiro M., Ogando D., Farina M., Franchi A. Epidermal growth factor modulation of prostaglandins and nitrite biosynthesis in rat fetal membranes. Prostaglandins Leukotrienes and Essential Fatty Acids, 2004, 70(1): 33-40 (doi: 10.1016/j.plefa.2003.08.003).

16. Samengo G., Avik A., Fedor B., Whittaker D., Myung K., Wehling-Henricks M., Tidball J. Agerelated loss of nitric oxide synthase in skeletal muscle causes reductions in calpain S-nitrosylation that increase myofibril degradation and sarcopenia. Aging Cell, 2012, 11(6): 1036-1045 (doi: 10.1111/acel.12003).

17. Li Y., Wang Y., Willems E., Willemsen H., Franssens L., Buyse J., Decuypere E., Everaert N. In ovo L-arginine supplementation stimulates myoblast differentiation but negatively affects muscle development of broiler chicken after hatching. Journal of Animal Physiology and Animal Nutrition, 2016, 100(1): 167-177 (doi: 10.1111/jpn.12299).

18. Tirone M., Conti V., Manenti F., Nicolosi P., D’Orlando C., Azzoni E., Brunelli S. Nitric oxide donor molsidomine positively modulates myogenic differentiation of embryonic endothelial progenitors. PLoS ONE, 2016, 11(10): e0164893 (doi: 10.1371/journal.pone.0164893).

19. Vanin A. EPR characterization of dinitrosyl iron complexes with thiol-containing ligands as an approach to their identification in biological objects: an overview. Cell Biochem. Biophys., 2018, 76(1): 3-17 (doi: 10.1007/s12013-017-0811-8).

20. Титов В.Ю., Косенко О.В., Старкова Е.С., Кондратов Г.В., Борхунова Е.Н., Петров В.А., Осипов А.Н. Ферментный сенсор позволяет определить недетектируемые другими методами формы доноров оксида азота в живых тканях. Бюллетень экспериментальной биологии и медицины, 2016, 162(7): 123-127 (doi: 10.1007/s10517-016-3557-1).

21. Titov V.Yu., Dolgorukova A.M., Fisinin V.I., Borkhunova Ye.N., Kondratov G.V., Slesarenko N.A., Kochish I.I. The role of nitric oxide (NO) in the body growth rate of birds. World Poultry Science Journal, 2018, 74(4): 675-686 (doi: 10.1017/S0043933918000661).

22. Tarpey M., Wink D., Grisham M. Methods for detection of reactive metabolites of oxygen and nitrogen: in vitro and in vivo considerations. American Journal of Physiology-Regulatory Integrative and Comparative Physiology, 2004, 286(3): R431-R444 (doi: 10.1152/ajpregu.00361.2003).

23. Hickok J., Sahni S., Shen H., Arvind A., Antoniou C., Fung L., Thomas D. Dinitrosyliron complexes are the most abundant nitric oxide-derived cellular adduct. Biological parameters of assembly and disappearance. Free Radic. Biol. Med., 2011, 51(8): 1558-1566 (doi: 10.1016/j.freeradbiomed.2011.06.030).

24. Severina I., Bussygina O., Pyatakova N., Malenkova I., Vanin A. Activation of soluble guanylate cyclase by NO donors-S-nitrosothiols, and dinitrosyl-iron complexes with thiol-containing ligands. Nitric Oxide, 2003, 8(3): 155-163 (doi: 10.1016/s1089-8603(03)00002-8).

25. Vanin A. Dinitrosyl iron complexes with thiolate ligands: physico-chemistry, biochemistry and physiology. Nitric Oxide, 2009, 21(1): 1-13 (doi: 10.1016/j.niox.2009.03.005).

26. Борхунова Е.Н., Кондратов Г.В., Титов В.Ю. Морфобиохимическая характеристика скелетных мышц кур на примере линий Б56 и Б79. Российский ветеринарный журнал. Сельскохозяйственные животные, 2014, 3: 22-30.

27. Винникова Э.З., Титов В.Ю. Определение фенотипически невыраженных форм страуса. Птицеводство, 2008, 12: 33-34.

\section{1ФНЦ Всероссийский научно-исследовательский} и технологический институт птицеводства РАН, Поступила в редакцию 141311 Россия, Московская обл., г. Сергиев Посад, ул. Птицеградская, 10, e-mail: anna.dolg@mail.ru,vtitov43@yandex.ru $\bowtie$, olga@vnitip.ru, oleg_kosenko@list.ru;

2ФГБОУ ВО Московская государственная академия ветеринарной медицины и биотехнологии-

МВА им. К.И. Скрябина,

109472 Россия, г. Москва, ул. Академика Скрябина, 23,

e-mail: prorector@mgavm.ru, ilnikonov@yandex.ru,omyasnikova71@gmail.com 


\title{
THE EMBRYONIC METABOLISM OF NITRIC OXIDE AND ITS INTERRELATION WITH POSTEMBRYONIC DEVELOPMENT IN CHICKEN (Gallus gallus domesticus L.) AND QUAILS (Coturnix coturnix L.)
}

\author{
A.M. Dolgorukova1, V.Yu. Titov', 2, I.I. Kochish', V.I. Fisinin'1, I.N. Nikonov', \\ O.V. Kosenko', O.V. Myasnikova ${ }^{2}$
}

\begin{abstract}
${ }^{1}$ Federal Scientific Center All-Russian Research and Technological Poultry Institute RAS, 10, ul. Ptitsegradskaya, Sergiev Posad, Moscow Province, 141311 Russia, e-mail anna.dolg@mail.ru, vtitov43@yandex.ru ( $\square$ corresponding author), olga@vnitip.ru,oleg_kosenko@list.ru;

${ }^{2}$ Skryabin Moscow State Academy of Veterinary Medicine and Biotechnology, 23, ul. Akademika K.I. Skryabina, Moscow, 109472 Russia, e-mail prorector@mgavm.ru, ilnikonov@yandex.ru, omyasnikova71@gmail.com ORCID:

Dolgorukova A.M. orcid.org/0000-0002-9958-8777

Titov V.Yu. orcid.org/0000-0002-2639-7435

Kochish I.I. orcid.org/0000-0001-8892-9858

Fisinin V.I. orcid.org/0000-0003-0081-6336

The authors declare no conflict of interests

Acknowledgements:

Supported financially by Russian Foundation for Basic Research, project No. 20-016-00204-a

Received May 10, 2020

Nikonov I.N. orcid.org/0000-0001-9495-0178

Kosenko O.V. orcid.org/0000-0002-9516-5769

Myasnikova O.V. orcid.org/0000-0002-9869-0876
\end{abstract}

\section{Abstract}

The embryonic development is accompanied by the intense synthesis of nitric oxide (NO). Many processes of the embryogenesis (e.g. tissue differentiation, apoptosis) were found to be NOdependent. However, due to the difficulties related to the control of NO metabolites in living tissues the physiological effects of NO have been studied by the indirect methods exclusively, via the effects of the inhibitors of NO synthesis or the effects of NO donor compounds and arginine as the precursor in the NO biosynthesis. But this does not allow us to establish the mechanism of the relationship between the observed effect and the metabolism of nitric oxide. Myogenesis is also considered NOdependent since arginine, NO-synthase inhibitors, and NO donors were reported to affect the development of muscles. However, these effects are quite contradictory. The lack of data on the relationship between nitric oxide metabolism and these effects does not allow us to suggest in detail the role of NO in myogenesis and the mechanism of its influence on muscle development. And the lack of understanding of this mechanism does not allow the use of nitric oxide to correct the animal development. In this study we are presenting a pioneer view on the interrelationships of embryonic NO metabolism with the features of the postembryonic body development in different poultry species determined with the use of highly sensitive and highly specific enzymatic sensor for determination of the NO metabolites. The study was aimed at the determination of interrelationships between the intensities of embryonic NO synthesis and its oxidation and embryonic and postembryonic body growth in poultry and at the evaluation of possible application of these interrelationships for the enhancement of meat productivity. The experiments were performed in 2017-2019 on different breeds of chickens and quails. It was found that the intensity of embryonic NO synthesis is similar within any given poultry species. In most cases no significant differences between the breeds $(p>0,05)$. This was determined by the total concentration of all NO metabolites in the embryo. However, the intensity of embryonic NO oxidation to nitrate can vary drastically. Differences between embryos of egg and meat breeds, lines and crosses on this indicator reach several orders of magnitude. In the embryos of egg breeds, there is mainly an accumulation of nitric oxide in the so-called donor compounds. By the end of embryogenesis, their concentration reaches several hundred of micromoles. In meat breed embryos NO is mainly oxidized to nitrate. The variance of the intensity of embryonic NO oxidation within a given breed does not exceed $10-15 \%$. This oxidation was found to occur predominantly in the embryonic muscle tissues. The intensity of NO oxidation is similar for endogenous (synthesized by embryos) and exogenous (injected in ovo) NO donors. The injections of inhibitors of NO synthesis decreased the embryonic concentration of total NO metabolites while the NO donors to nitrate ratio was not affected. These effects suggest that the intensity of NO oxidation to nitrate is directly correlated with certain features of embryonic tissues. Therefore, it can be considered as a biochemical marker of these features. It correlates with meat productivity and is an indicator inherent to a given to a given to a given breed. It is not sex-linked and does not depend on the layer age, nutrition, etc. Thus, it can be regarded as a highly sensitive and highly specific genetically preconditioned marker. The 2-fold increase or decrease of embryonic concentration of oxidized NO (by the intraembryonic injections of NO donors or inhibitors of NO synthesis, respectively) did not significantly affect the postnatal body growth rate. The exact mechanism of the embryonic NO oxidation and the interrelationships of the latter with the development of muscular tissues are still to be elucidated.

Keywords: poultry, nitric oxide, NO donors, nitrate, embryogenesis, post-embryonic growth. 